\title{
The Influence of Anxiety and Stress toward Depression in Institutionalized Elderly
}

\author{
Maria Manungkalit \\ Faculty of Nursing, Widya Mandala Catholic University Surabaya \\ maria-manungkalit@ukwms.ac.id \\ Ni Putu Wulan Purnama Sari \\ Faculty of Nursing, Widya Mandala Catholic University Surabaya \\ wulanpurnama@ukwms.ac.id
}

\begin{abstract}
Due to age-related changes, the elderly are prone to psychological problems, such as anxiety and stress, and mental disorder, such as depression. This study aimed to analyze the influence of anxiety and stress on depression in elderly living in the nursing home. This cross-sectional study involved I45 elderly in a private nursing home in Surabaya, Indonesia. Hamilton Anxiety Rating Scale (HARS), Suan Prung Stress Test - 20 (SPST-20), and Geriatric Depression Scale (GDS) were used for collecting data. Linear and ordinal regression tests were used in data analysis $(\alpha<0.05)$. Results showed that the majority was old married Chinese female with basic education level, and living in the nursing home for I-3 years. Averagely, respondents had mild anxiety, mild stress, and not depressed. Anxiety has significant influence on depression in elderly living in the nursing home $(p=0.000)$, and it was accounted for $12.8 \%$ variance of depression in this population $\left(R^{2}=0.128\right)$. Stress has a significant influence also on depression $(p=0.000)$, and it was accounted for $24 \%$ variance of depression in this population $\left(R^{2}=0.240\right)$. Stress is proved to have more influence on depression in the elderly living in the nursing home compared to anxiety.
\end{abstract}

Keywords: anxiety, depression, elderly, institutionalized elderly, nursing home, stress

Received 16 August 2019/Accepted 27 February 2020 CJEHCP All rights reserved

\section{Introduction}

Every individual will experience and face the aging process in their lifetime, which is a natural process that occurs both biologically and psychologically (Padila, 2013). The advent of global population ageing raises understandable concerns about the high-prevalence mental disorders or psychological problem in older people (Byrne \& Pachana, 2010).Psychological problems that are often found in the elderly are anxiety, stress, and depression (Stanley \& Beare, 2006). These three problems are considered as the negative emotional contructs (Wood, 2010). Psychological factors are the most dominant factor affecting quality of life (QOL) in the elderly, aside from physical, social, and environmental factors (Rohmah, et al., 20I2).In the context of living in a long-term care 
facility, such as nursing home, most of the elderly people feel depressed, alone, and disorganized (Marieanna \& Rene, 2009). Results of a systematic review towards 74 studies showed that dementia, depression and anxiety disorders are the most common psychiatric disorders among older adults living in long-term care (LTC) facility; many psychiatric disorders appear to be more prevalent in LTC settings when compared to those observed in community setting (Seitz, et al., 2010). Therefore, anxiety, stress, and depression in elderly who live in the nursing home needs special attention from various sectors, especially when the global tendency of population is becoming an ageing population. Policy-makers and clinicians should be aware about these and further research into effective prevention and treatments are required for this growing population.

Anxiety is an emotional condition that causes discomfort, characterized by feelings of worry, anxious, and fear, so that it can interfere with life (Setyaningsih, et al., 2017). Anxiety often occurs in the elderly as a result of various changes experienced by the aging process, for example physiological and psychosocial changes that have the potential to cause physical and psychological health problems (Setyaningsih, et al., 2017). There is a significant relationship between anxiety and QOL in the elderly who live in nursing homes (Setyaningsih, et al., 2017). Anxiety is also cause by the death and dying process related to old age, which influence by gender, education, social support, and self-esteem in nursing home residents (Azaiza, et al., 2010). Therefore, the level of anxiety needs to be assessed periodically in the nursing home.

Stress is the body's reaction to situations that cause pressure, change, and emotional tension (Koampa, et al., 20I5). Stressful person usually feels angry, anxious, sad, pessimistic, crying, irritable, having nightmares, impaired concentration and memory (Koampa, et al., 20I5). The elderly are prone to experience stress due to the common problems experienced by the elderly related to physical health, namely their susceptibility to various diseases due to reduced endurance in the face of outside influences (Koampa, et al., 2015). Low and declining functions in daily living and cognition constituted significant stressors among seniors and their spouse (Muramatsu, et al., 2010). There is a significant relationship between stress levels and QOL in the elderly who suffer from chronic disease, such as hypertension and diabetes mellitus (Azizah, 2016; Zainuddin, et al., 20l5). Therefore, the level of stress needs to be assessed periodically in the nursing home, especially in the elderly with chronic disease. 
Depression is a serious mental health problem involving symptoms related to mood, cognitive and physical symptoms (Pae, 2017). Factors that influence the occurrence of depression include biological factors, physical factors, psychological factors, and also social factors (Pae, 2017). Depression in the elderly can occur due to lack of support systems, age-related factors, factors of education level, health status and lack of activity from the elderly (Pae, 2017). There is a significant difference in the level of depression between the elderly who live in nursing homes compared to the elderly people who live with family at home in the community (Pae, 2017). Depression is the most prevalent mental health problem among older adults and it contributes to increase in medical morbidity and mortality, reduces $\mathrm{QOL}$ and elevates health care costs (Kumar, et al., 2014). There is a significant relationship between the level of depression and QOL in the elderly who live in nursing homes (Puspadewi \& Rekawati, 2017). Although the prevalence of depression in nursing homes to be high, under-recognition of depression in these facilities is widespread, the use of screening tests to enhance detection of depressive symptoms has been recommended (Snowdon, 2010). Therefore, the level of depression needs to be assessed periodically in the nursing home.

As psychological problems may result in mental disorder in elderly so there is a possibility that anxiety and stress may result in depression in this population. Previous study have shown that there is a significant difference in the level of depression between the elderly who live in nursing homes compared to the elderly people who live with family at home in the community (Pae, 2017), so the influence of anxiety and stress toward depression in elderly may differ also between both settings. This study aimed to analyze the influence of anxiety and stress toward depression in elderly living in the nursing home, as these three variables are highly prevalent in the elderly and tend to be more severe in institutionalized elderly. By knowing this study results, it will be beneficial for health care professionals to develop interventions targeting the decrease of anxiety and stress levels in order to reduce the prevalence of late life depression in institutionalized elderly.

\section{Method}

\section{Participants}

This cross-sectional study involved 145 elderly in a private nursing home in Surabaya, Indonesia. Inclusion criteria were at least 60 years old and having a family member as the one responsible for elderly care in the nursing home to be the contact person. Exclusion criteria were rejection on 
filling out the consent form, hospitalization, and impaired consciousness or disorientation. Total sampling was applied and sample size of I 45 was obtained.

\section{Measurement}

Hamilton Anxiety Rating Scale (HARS) [Hamilton, 1959] was used to assess anxiety level in study respondents. It consisted of 14 items in Likert scale format 0 fo to 4: $0=$ no symptom at all, $\mathrm{I}=\mathrm{I}$ symptom appears, $2=$ sufficient or $50 \%$ symptoms appear, $3=$ heavy or $>50 \%$ symptoms appear, and 4 = severe or all symptoms appear. The category of anxiety level was $0-18=$ mild anxiety, 19 37 = moderate anxiety, and $\geq 38=$ severe anxiety. The items were divided into anxiety response of mood, emotion, intellectuality, physical symptoms, somatic, and behavior during interview, for instance: item I "Worry, anticipate the worst, anticipate fear, irritability / sensitive," item 5 "Bad memory, concentration difficulties," and item 7 "pain, aching, throbbing, stiffness, jerking, teeth rattling, trembling sound, increased muscle tone." It is a valid and reliable instrument for measuring anxiety level $(r=.57-.84$; Cronbach's Alpha $=.93-.97)$ based on instrument testing procedure by Iskandar (1984).

Suan Prung Stress Test - 20 (SPST-20) [Mahatnirankul, Pumpisanchai \& Tapanya, 1997]was used to assess stress level in study respondents. It consisted of 20 items in Likert scale format of I to 5: I = no stress, $2=$ mild stress, $3=$ moderate stress, $4=$ high stress, and $5=$ severe stress. The category of stress level was $0-23=$ mild stress, $24-41=$ moderate stress, $42-61=$ high stress, and $\geq 62=$ severe stress. The items were divided into physical, psychological, and financial stress response, for instance: item 3 "There is a financial problem in my family," item I 3 “I felt frustrated,"and item I9 “I felt tired easily." It is a valid and reliable instrument for measuring stress level $(\mathrm{IOC}=.78$; Cronbach's Alpha $=.94)$ based on instrument testing procedure by Artsanthia \& Sari (2017).

Geriatric Depression Scale (GDS) [Yesavage, et al., 1982] was used to assess depression level instudy respondents. It consisted of 15 items in dichotomy scale format: "Yes" = I and "No" = 0 for item 2,3,4,6,8,9,10,12, 14, I5; while "Yes" = 0 and "No" = I for item I,5,7,II, I3. The category of depression level was $0-9=$ normal or undepressed state, $\geq 10=$ indicated depression. The items were divided into depression response of emotion, feeling, and spirit, for instance: item I "Are you actually satisfied with your life?" item 4 "Do you often feel bored?", and item I 3 "Do you feel full of 
enthusiasm?" It is a valid and reliable instrument for measuring depressionlevel $(r=.362-.717$; Cronbach's Alpha $=.94)$ based on instrument testing procedure bySuardana $(201 \mathrm{I})$.

\section{Data Collection}

Data were collected since February-May 2019. The data of anxiety and stress were normally distributed $(p=0.059$ and $p=0.080$ respectively), while the data of depression was not $(p=0.02 I)$. The data of anxiety was linear to depression $(p=0.410)$, therefore simple linear regression test was used in data analysis; while the data of stress was not linear to depression $(p=0.003)$, therefore ordinal regression test was used in data analysis $(\alpha<0.05)$. Ethical clearance was issued by Faculty of Medicine, Widya Mandala Catholic University Surabaya, Indonesia, with certificate number of 0I0/WMI2/KEPK/T/20I9.

\section{Results}

There were 145 elderly participated in this study. Most of them were old individuals (75-90 years old), female, married, Chinese, secondary school graduated, and living in the nursing home for I-3 years. Table I below explains the demography characteristic of study respondents in details.

Table I

Demography Characteristic

\begin{tabular}{clcc}
\hline No. & \multicolumn{1}{c}{ Characteristic } & Frequency & Percentage (\%) \\
\hline I & Age (Years Old) & & \\
& A. Pre-Elderly (45-59) & 9 & 6.20 \\
& B. Elderly (60-74) & 65 & 44.82 \\
& C. Old (75-90) & 68 & 46.89 \\
& D. Very Old (>90) & 3 & 2.06 \\
\hline 2 & Gender & & \\
& A. Male & 71 & 48.96 \\
& B. Female & 74 & 51.03 \\
\hline 3 & Marital status & & \\
& a. Single & 33 & 22.75 \\
& b. Married & 58 & 40.00 \\
& c. Separated / divorced & 9 & 6.20 \\
& d. Widowed & 45 & 31.03 \\
\hline 4 & Ethnicity & & \\
& a. Javanese & 57 & 37.93 \\
& b. Maduranese & & 6.89 \\
& c.. Chinese & 10 & 52.41 \\
d. Others & 76 & 2.75 \\
\hline
\end{tabular}


$5 \quad$ Educational background
a. Primary school
29
20.00
b. Secondary school
34.48
c. High school
50
30.34
d. University graduated
44
11.03
e. Uneducated
19
2.06

6 Period of living in nursing home (years)
a. $<1$
33
22.75
b. I-3

$59 \quad 40.68$
c. $>3-6$
41
28.27
d. $>6$
12
8.27

Results of descriptive statistic showed that averagely respondents had mild anxiety (Mean \pm SD: $16.78 \pm$ 13.69), mild stress (Mean \pm SD: $23.14 \pm$ 15.18), and not depressed (Mean \pm SD: $8.49 \pm$ 2.77). Regression test results showed that anxiety has significant influence on depression in elderly living in the nursing home $(p=0.000)$, and anxiety accounted for $12.8 \%$ variance of depression in this population $\left(R^{2}=0.128\right)$. Stress has significant influence also on depression $(p=0.000)$, and stress accounted for $24 \%$ variance of depression in this population $\left(R^{2}=0.240\right)$. Stress was proved to have more influence on depression in elderly living in the nursing home compared to anxiety. Table 2 explains the results of statistical test. Further nursing assessment should emphasize more on early detection of stress in the elderly, and nursing intervention needs to address stress management in various methods applicable in the context of elderly care in nursing home.

Table 2

Results of Statistical Analysis

\begin{tabular}{llcc}
\hline \multicolumn{1}{c}{ Model } & $\mathrm{R}^{2}$ & Adjusted $\mathrm{R}^{2}$ & Sig. \\
Anxiety*Depression & .128 & .122 & 0.000 \\
Stress*Depression & .240 & .124 & 0.000 \\
\hline
\end{tabular}

\section{Discussion}

Results showed that anxiety had significant influence on depression in elderly living in the nursing home. This finding is supported by Drageset's et al, (2012) study towards 227 nursing home residents (>65 years old) which showed that twice as many residents had symptoms of depression, anxiety, and both.In late life, anxiety and depression have a high prevalence, co-occur frequently, 
and have a significant effect on well-being (QOL) and functioning; both disorders are associated with excess rates of mortality, and have considerable economic ramifications (van't Veer-Tazelaar, et al., 2009). Among individuals aged 90 years, depression and anxiety and their co-occurrence are highly prevalent, but anxiety does not add to poor functional status and increased mortality beyond that associated with depression (Van der Weele, et al., 2009). Results of a comprehensive review showed that: (a) anxiety disorders are common among older age individuals; (b) overlap exists between anxiety symptoms of younger and older adults; and (c) anxiety disorders are highly comorbid with depression in older adults (Wolitzky-Taylor, et al., 2010). In bigger/larger private nursing homes, some undetected depression may happen, but this undetection of depression may decrease in residents with anxiety (Damian, et al., 2010; Rashedi, Gharib, Rezaei, \&Yazdani, 2013).

Most respondents in this study are old females aged 75-90 years old (46.89\%). Systematic review and meta-analysis have shown that there is a correlation between old age $(75+)$ and female gender with the incidence of latest life depression (Luppa, et al., 2012).). Depressive symptoms decline and under-treatment increases with age both in institutionalized and community-dwelling elderly (Ellis, 2010; Grav, Hellzen, Romild, \& Stordal, 2012). A longitudinal study towards 67I nursing home residents showed that depression was found together with higher age, worse physical health, poor function in daily activities; predictors of depression incidence at 12 months were a shorter stay in nursing home, while for depression persistence was unmarried / single (Barca, et al., 20I0). In this study, we found $22.75 \%$ respondents who were single and stay in the nursing home less than a year. A study towards 902 nursing home residents showed that female gender and unmarried marital status were associated with depressive mood, while depression was associated with worse medical health and cognitive impairment (Barca, et al., 2009). Newly admitted people with mental illnesses were younger and more likely to become long-stay residents in nursing home than those admitted with other conditions. Taken together, state-level mental health and nursing home factors may influence the likelihood of long-term nursing home use for people with mental illnesses (Grabowski, et al., 2009).

Results showed that stress also had significant influence on depression in elderly living in the nursing home. There is very few literatures related to the study findings as not so many studies conducted in the area of stress and its influence on depression in the elderly found online. But, in the context of general ageing population, this finding is supported by a study in Germany towards 1,659 elderly 
(60-85 years old) which showed that stress, especially post-traumatic stress disorder, is usually comorbid with depression and somatisation in the elderly (Glaesmer, et al., 20I2).Another longitudinal study towards 193 elderly $(85+)$ in community context showed that stress and psychosocial resources play a crucial role in late-life depression; changes in positive life events, daily hassles (worries), and mastery were significantly associated with changes in late-life depression among the oldest-old (Jeon \& Dunkle, 2009).There is evidence about how stress reduction intervention could reduce depression significantly in nursing home residents (Kumar, et al., 20I4; Haugan, Innstrand, \& Moksnes, 20I3; Haugan, 20I4); the results of a systematic review concluded that stress management intervention significantly effective for reducing depression (D'Silva, et al., 2012); and the results of literature review concluded that strategies of coping are significantly associated with depressive symptoms in late life (Bjorklof, et al., 20I3); which is indicated that stress has significant influence on depression in institutionalized elderly. Although often associated with the stress and physical problems attendant with advancing age, depression is not a normal part in older individuals' life (Wienclaw \& Mitchell, 2019).

In this study we found mostly old individuals (75-90 years old), secondary school graduated (basic education), having no income at the moment, and mostly engaged in religious activity in the nursing home. The protective factors of depression include higher education and socioeconomic status, engagement in valued activities, and religious or spiritual involvement (Fiske, et al., 2009). Most study respondents have low education level and socioeconomic status, but results showed that the majority has no depression (GDS: Mean \pm SD: $8.49 \pm 2.77)$. A review of depression in older adults suggests that the common pathway to depression in elderly, regardless of which predisposing risks are most prominent, may be curtailment of daily activities. Accompanying self-critical thinking may exacerbate and maintain a depressed state. Offsetting the increasing prevalence of certain risk factors in late life are age-related increases in psychological resilience. Risk factors leading to the development of late-life depression likely comprise complex interactions among genetic vulnerabilities, cognitive diathesis, age-associated neurobiological changes, and stressful events. Stressful events that involve threats to competence (eg, functional and cognitive declines) may predispose an individual to late-life depression through stress-related hormones (Fiske, et al., 2009).

Results showed that stress has stronger influence on depression compared to anxiety in elderly living in the nursing home. This finding indicates that the decline in physical health, high susceptibility 
to various diseases, cognitive impairment, low and declining functions in daily living which result in stress have stronger influence on late life depression in nursing home residents compared to the age-related changes (physical and psychological), death and dying process which result in anxiety. By knowing this fact, nurses working in the nursing home are recommended to do continuous stress and depression screening periodically, especially to the elderly with cognitive impairment, impaired daily functioning, and having chronic disease. Therefore, the $\mathrm{QOL}$ in institutionalized elderly could be maintained in the optimum level.

\section{Conclusion}

In the old individuals living in the nursing home, mild anxiety, mild stress, and not depressed state were found in the majority. Anxiety has significant influence on depression in elderly living in the nursing home, and it was accounted for $12.8 \%$ variance of depression in this population. Stress has significant influence also on depression, and it was accounted for $24 \%$ variance of depression in this population. Stress is proved to have more influence on depression in elderly living in the nursing home compared to anxiety.

\section{Acknowledgement}

This study was supported for publication by Faculty of Nursing, Widya Mandala Catholic University Surabaya.

\section{References}

Artsanthia, J., \&Sari, N. P. W. P. (2017). Study Report:The Effect of Meditation Healing Exercise in Elderly Who are Living With Non-Communicable Disease in Bangkok and Surabaya. Bangkok: Faculty Of Nursing, Saint Louis College.

Azaiza, F., Ron, P., Shoham, M., \& Gigini, I. (2010). Death and dying anxiety among elderly Arab Muslims in Israel. Death Studies, 34(4), 35I-364.

Azizah. (2016). The 4 University Research Coloquium 2016. Retrieved from: https://publikasiilmiah.ums.ac.id/bitstream/handle/I 1617/7766/Mahasiswa\%20(Student\%20Paper\% 20Presentation)(1) 31.pdf?sequence $=1$

Byrne, G. J., \& Pachana, N. A. (2010). Anxiety and depression in the elderly: do we know any more? Current Opinion in Psychiatry, 23(6), 504-509.

Barca, M. L., Selbaek, G., Laks, J., \& Engedal, K. (2009). Factors associated with depression in Norwegian nursing homes. Geriatric Psychiatry, 24(4), 4I7-425.

Barca, M. L., Engedal, K., Laks, J., \& Selbaek, J. L. (2010). A 12 months follow-up study of depression among nursing-home patients in Norway. Journal of Affective Disorders, I20(I-3), |4|-|48. 
Bjorklof, G. H., Engedal, K., Selbaek, G., Kouwenhoven, S. E., \& Helvik, A. S. (20I3). Coping and depression in old age: a literature review. Dementia and Geriatric Cognitive Disorders, 35(3-4), I2I-I54.

Damian, J., Pastor-Barriuso, R., \&Valderrama-Gama, E. (2010). Descriptive epidemiology of undetected depression in institutionalized older people. Journal of the American Medical Directors Association, II(5), 3I2-319.

Drageset, J., Eide, G. E., \& Ranhoff, A. H. (2012). Anxiety and depression among nursing home residents without cognitive impairment. Scandinavian Journal of Nursing Sciences, 27(4), 872-88I.

D'Silva, S., Poscablo, C., Habousha, R., Kogan, M., \& Kligler, B. (2012). Mind-body medicine therapies for a range of depression severity: a systematic review. Psychosomatics, 53(5), 407-423.

Ellis, J. M. (2010). Psychological transition into a residential care facility: older people's experiences. JAN, 66(5), II59-II68.

Fiske, A., Wetherell, J. L., \& Gatz, M. (2009). Depression in older adults. Annual Review of Clinical Psychology, 5, 363-389.

Glaesmer, H., Kaiser, M., Braehler, E., Freyberger, H. J., \& Kuwert, P. (20I2). Posttraumatic stress disorder and its comorbidity with depression and somatisation in the elderly - A German community-based study. Aging \& Mental Health, 16(4), 403-4I2.

Grabowski, D. C., Aschbrenner, K. A., Feng, Z., \& Mor, V. (2009). Mental illness in nursing homes: variations across states. Health Affairs, 28(3), DOI: https://doi.org/I0.1377/hlthaff.28.3.689

Grav, S., Hellzen, O., Romild, U., \& Stordal, E. (20I2). Association between social support and depression in the general population: the HUNT study, a cross-sectional survey. Journal of Clinical Nursing, 2 I (I-2), I I I-I 20.

Haugan, G., Innstrand, S. T., \& Moksnes, U. K. (2013). The effect of nurse-patient interaction on anxiety and depression in cognitively intact nursing home patients. Journal of Clinical Nursing, 22(15-16), 2192-2205.

Haugan, G. (20/4). Nurse-patient interaction is a resource for hope, meaning in life and self-transcendence in nursing home patients. Scandinavian Journal of Caring Sciences, 28( I), 74-88.

Hamilton, M. (1959). The assessment of anxiety states by rating. $\mathrm{Br} J$ Med Psychol, 32, 50-55.

Iskandar, Y. (1984). Biologic Psychiatry and Depression and Anxiety: Diagnosis and Therapy for General Practice (in Bahasa Indonesia). Jakarta: Yayasan Dharma Graha.

Jeon, H-S., \& Dunkle, R. E. (2009). Stress and depression among the oldest-old: a longitudinal analysis. Research on Aging, 3I(6), 66I-687.

Koampa, M. M., Bidjuni, H., \&Onibala, F. (20I5). Correlation between stress level and independency level in elderly, Tombasian village, West Kawangkoan district (in Bahasa Indonesia).ejournal Keperawatan (e-Kp), 3(2), I-6.

Kumar, S., Adiga, K. R., \& George, A. (2014). Impact of mindfulness-based stress reduction (MBSR) on depression among elderly residing in residential homes. The Nursing Journal of India, 105(6), 248-25I. 
Luppa, M., Sikorski, C., Luck, T., Ehreke, L., Konnopka, A., Wiese, B., Weyere, S., Konig, H. H., \& Riedel-Heller, S. G. (20I2). Age- and gender-specific prevalence of depression in latest-life Systematic review and meta-analysis. Journal of Affective Disorders, I36(3), 212-22I.

Marieanna, C. L. R., \& Rene, K. E. M. P. (2009). Effect of a companion dog on depression and anxiety levels of elderly residents in a long-term care facility. psychogeriatrics, 9(I), 23-26.

Mahatnirankul, S., Pumpaisanchai, V., \&Tapanya, P. (1997). The construction of Suan Prung Stress Test for Thai population. Bulletin of Suan Prung, I3(3), I-I I.

Muramatsu, N., Yin, H., \& Hedeker, D. (20I0). Functional declines, social support, and mental health in the elderly: Does living in a state supportive of home and community-based services make a difference?Social Science \& Medicine, 70(7), 1050-1058.

Padila. (2013). Nursing Care Plan for Internal Disease (in Bahasa Indonesia). Yogyakarta: Nuha Medika.

Pae, K. (2017). Differences of depression level between elderly lives in the nursing home and at home with families (in Bahasa Indonesia).Jurnal Ners Lentera, 5(I), 2I-32.

Puspadewi, A. A. A. R., \&Rekawati, E. (2017). Depression is associated with quality of life in the nursing home of Tresna Werdha, Jakarta (in Bahasa Indonesia).Jurnal Keperawatan Indonesia, 20(3), 133-138.

Rashedi, V., Gharib, M., Rezaei, M., \&Yazdani, A. A. (2013). Social support and anxiety in the elderly of Hamedan, Iran. Journal of Rehabilitation, I4(2), II0-I I 5.

Rohmah, A. I. N., Purwaningsih., \&Bariyah, K. (20I2). Quality of life in the elderly (in Bahasa Indonesia). Jurnal Keperawatan, I20-I 32.

Seitz, D., Purandare, N., \& Conn, D. (2010). Prevalence of psychiatric disorders among older adults in long-term care homes: a systematic review. International Psychogeriatric, 22(7), 1025-1039.

Setyaningsih, E., Setiyawan., \&Saelan. (2017). Correlation between anxiety and quality of life in nursing home of Dharma Bhakti Kasih, Surakarta (in Bahasa Indonesia). Retrieved from: http://digilib.stikeskusumahusada.ac.id/repo/disk I/29/0 I-gdl-endangsety-I443-I-naskahp-h.pdf

Snowdon, J. (2010). Depression in nursing homes. International Psychogeriatrics, 22(7), I I 43-I I 48.

Stanley, M., \&Beare, P. G. (2006). Textbook of Gerontology Nursing (in Bahasa Indonesia). Jakarta: EGC.

Suardana, I.W. (20II). Bachelor Thesis: Correlation Between Socio-demographic Factor, Social Support, and Health Status with Depression Level in Aggregate of Elderly in Sub-district of Karangasem, District of Karangasem, Bali (in Bahasa Indonesia).Jakarta: Universitas Indonesia. 
Szczerbinska, K., Hirdes, J. P., \& Zyczkowska, J. (20I2). Good news and bad news: depressive symptoms decline and undertreatment increases with age in home care and institutional settings. The American Journal of Geriatric Psychiatry, 20( I2), I045-I056.

Van der Weele, G. M., Gussekloo, J., De Waal, M. W. M., De Craen, A J. M., \& Van der Mast, R. C. (2009). Co-occurrence of depression and anxiety in elderly subjects aged 90 years and its relationship with functional status, quality of life and mortality. International journal of Geriatric Psychiatry, 24(6), 595-60I.

van't Veer-Tazelaar, P., van Marwiik, H. W. J., van Oppen, P., van Hout, H. P J., van der Horst, H. E., Cuiipers, P., Smit, F., \& Beekman, A. T. F. (2009). Stepped-care prevention of anxiety and depression in late life: a randomized controlled trial. Arch Gen Psychiatry. 66(3), 297-304.

Wienclaw, R. A., \& Mitchell, M. A. (2019). Late-life depression. The Gale Encyclopedia of Mental Health, 932-936.

Wolitzky-Taylor, K. B., Castriotta, N., Lenze, E. J., Stanley, M. A., \& Craske, M. G. (2010). Anxiety disorders in older adults: a comprehensive review. Depression \& Anxiety, 27(2), 190-21 I.

Wood, B. M., Nicholas, M. K., Blyth, F., Asghari, A., \& Gibson, S. (2010). The utility of the short version of the Depression Anxiety Stress Scales (DASS-2I) in elderly patients with persistent pain: does age make a difference? Pain Medicine, II (I2), I780-I790.

Yesavage, J. A., Brink, T. L., Rose, T. L., Lum, O., Huang, V., Adey, M., \& Leirer, V. O. (1982). Development and validation of a geriatric depression screening scale: a preliminary report. $J$ Psychiatr Res., 17(1), 37-49.

Zainuddin, M., Utomo, W., \&Herlina. (20I5). Correlation between stress and quality of life in type 2 diabetes mellitus (in Bahasa Indonesia). JOM, (2)I, 890-898. 